\title{
Eco-city Objectives: A Framework for Formulation and Examination Based on the Planning Perspective
}

\author{
Lili Ma \\ School of Economics \& Management, Lanzhou Jiaotong University \\ Lanzhou 730070, P. R. China \\ Email: 13919000080@163.com
}

\begin{abstract}
A framework for objective examination of eco cities has not been systematically constructed. The framework can guide eco-city planning, construction and implementation through developing an ultimate checklist for assessment of eco-city performance. The article firstly analyzes general objectives and sub objectives of eco-city. Based on this, the paper presents an objective examination framework of eco-city by using the Delphy consultation, expert group discussion, case investigation and other methods. The framework has 3 criterion layers. Finally, the research explores several relatively innovative and integrative policies for eco-city planning. By developing an examination framework for eco-city objectives the checklist can be formulated to popularize the concept of eco-city development and promote best practice to encourage and facilitate the exchange of experiences between cities.
\end{abstract}

Keywords-Eco-city; Resource efficiency; Friendly environment; Sustainable economy; Social harmony

\section{INTRODUCTION}

Eco-city is the present mainstream aspect of urban development. Living in an economically sustainable, socially harmonious, environmental friendly and resource-conserving city has become a common demand of urban inhabitants'.

Despite the popularity of eco-city research among international and national policy programs and institutions, the defining features and objectives of an eco-city are always questioned. An Objective framework for examination and a scoring methodology of eco-city are still lacking.

The aim of this paper is to develop an objective examination framework which formulates the key objectives eco-city should ultimately achieve. By applying research methods like causal research, evaluation research, correlation research and case study research, this paper firstly lists and analyzes objectives of eco-city in section two following the introduction. And he paper presents an objective examination framework of eco-city by using the Delphy consultation, expert group discussion, case investigation and other methods. In section four, several relatively innovative and integrative policies for eco-city planning are critically reviewed.

\section{ECO-CITY OBJECTIVES}

Based on the principles of creating an eco-city, eco-city concept and features, a classification framework for eco-city objectives is determined. Generally, three objectives need to be achieved during eco-city construction: friendly environment, sustainable economy and social harmony. The following segments will present the objectives related to the features of an eco-city. Also, the subsequent text will explain the objectives and their relevance to establish a framework for examination of eco-city objectives.

\section{A. Friendly environment objective}

\section{1) Land Resources}

Urban sprawl control and cultivated land protection

Reduce land and new constructions demand

Compact, polycentric and transit-oriented city structure

Qualified high building density

New city projects indirectly contribute to urban sprawl. Alongside the urban extension, lots of farmland is occupied to satisfy construction land demand. Thus, eco-city should be a kind of infill development, which implies a densification within the existing urban structures without extending outwards [1]. Brownfield sites and existing buildings should be reused and transformed if they are appropriately located. Eco-city should aim to organize a mix of residential, employment, educational and entertainment uses as well as the combination of distribution, supply and entertainment facilities. Eco-city development should be creating a polycentric city structure to establish a network of mixed-use city land and achieve a city that enables short distance travel to several facilities. Specifically, the objective of land use planning is to encourage mixed land use and sensitive integration of land use with the surrounding urban context. Also, the community site should be planned to access public transport, the CBD and the adjacent network of educational and cultural institutions. Transport-oriented development should be considered for eco-city, to enable connectivity between residential, commercial, open space and public uses in a walkable environment, to make it convenient for residents and employees to travel by public transport, bicycle, foot, or car. Compact building-structures are another significant means of reducing demand for land. Multi-storey residential, commercial or mixed-use buildings need to be considered instead of detached and single-family houses with large gardens. 


\section{2) Energy}

Improve energy efficiency

Reduce buildings' energy demand

Maximize renewable energy usage proportion

Improving the energy efficiency of the urban structure is a relatively cost-effective measure to save energy. The way should be considered at the early stage of urban planning [2]. Planners should highly strive for compact city which contributes to minimizing travel demand and further saving energy. Also, they should focus on a compact building structure like apartment blocks or rows of terraced houses because compact building structure helps to implement centralized heating system that is a way to achieve improving energy efficiency. Secondly, on the urban scale, combined heat and power (CHP) plants are the most efficient energy supply system to provide heating and electricity. Among equipment and systems, the quality of the HVAC (heating, ventilating and air-conditioning) equipment plays an important role in achieving efficient use of energy. It is recommended to use decentralized heating systems based on ground heat exchange, solar powered hot water and electricity production and sophisticated ventilation systems [3]. Thirdly, minimizing energy can be achieved through maximum natural lighting. Specifically, 'building should face the sun; roofs should be suitable for active solar facilities such as photovoltaic panels and shading of facades should be prevented both by optimizing the distances between buildings and by considering the position of trees' [4]. Besides, a high level of thermal insulation and air-tightness is an efficient passive energy saving to reduce energy demand. Combined with good ventilation opportunities and systems, this could be supported by compact building design and a reasonable windows arrangement. This contributes to maximizing solar gains and reducing the energy demand for cooling [5]. Renewable energy could be used for heating, cooling, domestic hot water and street lighting. It is relatively efficient, contributing to IEQ (indoor environmental quality) enhancement, and the return of investment is usually achieved in a short period of time. In combination with CHPs, renewable energies like sun, wind and biomass can be used for electricity generation towards a low or even zero emission neighborhoods.

\section{3) Water Resources}

Optimize water resources use

\section{Minimize the negative impact on local water recycle}

Optimizing water resources use can be achieved through effectively managing supply and demand as well as water-saving strategy. Water treatment plants are necessary for satisfying the water demand in the eco-city. These plants are usually surface water treatment plants that utilize conventional treatment processes, including coagulation and sedimentation followed by filtration and chlorine disinfection[6]. Besides, water saving strategy contributes to the primary water consumption reduction. Rainwater collection and recycling is another effective measure to minimize the primary water use. For urban landscape, green space management should be heavily concerned. For example, plants and trees should be chosen due to little requirement for large amount of water. Preserving the environment can be achieved through ensuring proper wastewater and storm water management and high rates of water reclamation and reuse.

\section{4) Building Materials}

Reduce primary building materials consumption

Maximize reusable, renewable, and recyclable materials

Maximize environmentally friendly and healthy materials

Reduction of the consumption of primary building materials is a significant start point to reduce resource use from urban development. It contributes to minimizing mining of local resources to protect urban ecosystem, and benefits minimizing $\mathrm{CO}_{2}$ emission generated from raw materials transportation. The choices of building materials greatly contribute to a project's sustainability and then have profound impact on the eco-efficiency of city. Because appropriate material selection can minimize the depletion of resources, including raw materials, such as wood and metals, as well as embodied energy of building materials. It benefits in supporting ecological diversity and balance. Thus, maximizing the proportion of reusable, renewable and recyclable materials should be an aim while designing building components and selecting building materials. Also, designers should give priority to building materials with the high durability, easy detachability, practicable reusability and practicable material recovery. Besides renewable and recyclable materials, other environmentally friendly and healthy building materials are motivated to use. The use of natural and renewable materials such as timber, clay and straw could minimize the negative impact of building on natural environment. The use of local or regional materials such as local stone, brick and timber makes contribution to energy saving in transporting building materials The use of harmless materials such as PVC-free installations and solvent-free paint helps to improve indoor environment quality and then enhance well-being of dwellers [3].

\section{5) Bioclimatic Conditions}

Climatic, topographical and geological setting

The context for human settlement is provided by the natural environment on the regional scale. The natural environment of a settlement encompasses the climatic, topographical and geological setting. To achieve high-quality bioclimatic conditions, the climate needs to be considered such as air exchange systems on the urban scale. Besides, local topographical factor is associated with planning for establishing the smooth integration of pathways to provide comfortable walking and cycling conditions. Geological aspects (e.g. soils and groundwater system) relates to drainage system, construction site and urban landscape such as selection of species for planting. 


\section{6) Landscape and Green Spaces}

Landscapes and natural elements conservation

Sustainable use of natural elements and landscape

Zero net loss of natural wetlands

Landscape conservation is an essential objective for eco-city planning. As the characteristics of the natural environment, ecosystems, habitats and species should be maintained and reinforced differently from regions, and thus be protected from lasting detrimental and destructive impacts. Also, natural resources should be used in a sustainable way for economic and social purpose since they make an important contribution to resident's life quality improvement and economic development. For example, as leisure areas connected to city quarters, surrounding landscapes can provide inhabitants alternatives to recreational activities away from their settlements. Surrounding landscapes can also drive the development of ecological tourism and thus lead to added economic benefits. Among various natural elements, it is worthy focusing on the impact of water elements (e.g. streams, ponds and lakes) on urban system as well as reducing net loss of natural wetlands.

\section{7) Transport Models}

Give priority to public transport network and services

\section{Attach importance to pedestrians and cyclists}

An environmentally friendly transport share mode is one of the major objectives of eco-city. Giving priority to public transport network and services is basic requirement to achieve this goal. Multi-modal integrated public transport network with different tiers does not only help to promote connectivity between various urban functional areas but also provide accessibility to surrounding areas. Moreover, public transport services need to be highly concerned. According to Newman (2005), it involves taking a helpful approach towards public transport both in the planning process and in the implementation stage. For instance, since accessibility is an important indicator for assessing the competitiveness of transport mode, public transport services should be available and easy both in space and in time [8]. Specifically, it should strive for short access to stops and short waiting times. Furthermore, a number of other factors like the affordability, speed, and comfort and information provision of public transport can influence the transport modal choice of those who make journeys. Also, it is more likely that public transport will be the preferred mode if public transport stops is with high accessibility. Pedestrian and cyclist priority schemes contribute to environmentally friendly transport modes. It aims to make walking and cycling as alternatives to motorized transport through improving attractiveness and usability of them. For instance, it is practical providing routes for walking and cycling in the grassroots community, and these routes connect the community with public facilities that inhabitants visit on a daily basis. Other sidewalk and bikeway could be adjacent to the grid road system. Thus, a dense, high-quality and supply-oriented infrastructure network should be provided for pedestrians and cyclists in order to offer direct access to pedestrian and bicycle facilities.

\section{8) Transport Management Systems}

Reduce motorized traffic through parking management

Support environmentally friendly transport models

To implement sound parking management is another way to reduce individual motorized travel. Planners aim to minimize the overall provision and impact of car parking for properties surrounding and within the public domain through the use of a communal car park and shared car parking spaces. Also, neighborhood car parks should be concentrated rather than car parks provided on street or in association with individual house, unit or apartment. Providing the levels and quality of public services are relatively high, individual motorized travel tends to be reduced if the accessibility of the nearest public transport stops for most inhabitants are better than that of the nearest parking space. Secondly, mobility management measures play a positive role in supporting the modal shift to environmentally compatible modes. This can be achieved through 'awareness-raising campaigns, internet platforms on travel options and mobility centers with comprehensive support for transportation requirements (e.g. mobility help desk, agency for arranging lifts, car-sharing garage, bicycle hire system and public transport ticket sales)' [8].

\section{9) Waste \\ Minimize waste generation}

\section{Optimize waste treatment}

Minimizing waste generation can be achieved by waste reduction initiatives. For instance, two measures for reducing solid waste quantity are proposed including food sales and packaging control. Besides, consumers' purchasing habits change is the most efficient mechanism to reduce the generation of domestic waste. It can be promoted by encouraging sharing rarely used items like travel facilities instead of ownership of them. Secondly, optimizing waste treatment is a significant target because it is important for creating a sanitary urban environment. Rubbish classification becomes imperative. Dustbin design and its functions should also be changed. In addition, 'A necessary prerequisite is the provision of easily accessible and well-serviced areas for separating collection of glass, paper, plastic and metal' [3]. Moreover, recycling and recovery largely contribute to reducing disposed waste quantities and returning materials to new production. Additionally, hazardous waste treatment should be highly focused on. Classified treatment is needed to minimize the detriment of hazard waste and improve recyclability and reusability. 


\section{B. Sustainable economy objective}

\section{1) Economic Development}

Vibrant local economy

Economy with opportunities for enterprise \& innovation

From aspect of economic development, eco-city is envisioned as an economically sustainable city. It aims to strive for vibrant economic hub providing good jobs and opportunities for enterprise and innovation. Economic development in eco-city is a process by which city can initiate and generate its own solution to its common economic problems and therefore build a long-term urban capacity and promote the integration of economic, social and environmental targets. Vibrant local economy can be achieved through industrial structure optimization, sufficient employment opportunities creation and self-support capability of community economy. Besides, improving labor force skill and knowledge is significant for attaining vibrant local economy. Additionally, especially in China, it is not ignored that eco-city project is usually a complex partnership between private and public entities both in national and international scope. Commercial pressures with respect to economic and real estate development would be great[8]. Thus, how to balance commercial interests and public interests could be a continuing challenge and need cautious decision-making. This can ensure that eco-city project investments are financed for long term. This further indirectly promotes achieving an economically sustainable city.

\section{Social Harmony Objective}

1) Public Space

Provide comfortable and attractive public spaces

Livability, legibility and connectivity

Increase public green space per capita

Creating landscape patterns with high social usability

Comfortable and attractive public spaces for daily life are a central element of eco-city and they could be used as multi-functional places for commercial activities, social contacts and entertainment etc. Planners intend to establish diverse and sustainable public spaces, plazas and parks which contribute to social interaction and cohesion [9]. Besides, it is important to focus on public domain design and planning for pedestrian amenity and safety by providing recreation areas, a sense of place, social networking and community. It also benefits to improve a distinctive community identity that reflects local area diversity. And eco-city planning should consider maximizing livability, legibility and connectivity of public space patterns. This implies urban space should be designed with active building frontages, and visible, well-articulated, and understandable. Also, public spaces should provide residents safety, security and easy accessibility. Besides, in order to increase public green space per capita, eco-city planning should maximize green outdoor areas volume, roofs and facades and their ecological quality, and keep larger green zones and building layouts around existing green spaces. Besides, landscape patterns should also be created for providing a hierarchical structure with private gardens, semi-public courtyards and public parks and further their high social usability [10]. It can make sport and other leisure activities happen in the surrounding green space including private, semi-public and public green spaces to reduce the demand for new recreational facilities and leisure travel.

\section{2) Travel Demand}

Reduce distances between activities

Provide efficient connectivity to key centers

Inhabitants' activities and their location have direct impact on travel demand. Thus, the most effective measure for minimizing travel demand is to reduce distance between various activities in time and space. Developing a city as a relatively high-density city is an effective way to promote transit oriented development (TOD). It successfully provides a greater mix of land use and diversity. Besides, TODs indirectly contributes to carbon footprint reduction through reducing vehicle-trips, and it benefits to increasing public transport use and decreasing private vehicles use. Since inhabitants tend to reduce overall demand for travel and use environmentally friendly modes if residential, retail, office, open space and public spaces are in a walkable environment. Moreover, effectively integrated land use and urban transit planning also contribute to reducing personal motorized transportation demand. It enables inhabitants to apply the environmentally friendly modes for short to medium distances, which are faster and cheaper for daily travel and further helps to increase residents' living quality. Secondly, providing efficient connectivity to key centers is an important way to minimizing unnecessary travel through providing a comprehensive, fully-integrated public transit system with a high level of community accessibility as well as delivering a regional transport strategy [7]. Moreover, it should link with the city's planned land use such as key center layout, and also formulate a functional and mass transit plan that best meets land use requirements. This can have indirect positive influence on saving time and space between activities due to short distance and better connectivity to key centers, and thus reducing overall distance. Also, cooperating with planned land use, a functional and mass transit plan contributes to creating efficient urban transportation system and thus providing residents more convenient daily life.

\section{3) Social Development}

Social harmonious and inclusive communities

Inhabitants' strong sense of ownership \& belonging

Provide quality services with good accessibility

To achieve Social harmony, inclusive communities should be highly concerned because community is a significant element of the whole society. They could contribute to promoting social cohesion, social integration. It also provides residents more attractive and high-quality living. For instance, in a community, neighborhood quality is related to social cohesion, trust sense and collective efficacy [10]. Secondly, the inhabitants' sense of ownership \& belongings needs to be paid attention to. Taking housing affordability as an example, it is one of the imperative aspects closely related to this kind of 
sense. A deficiency of affordable housing has negative impact on the competitiveness and efficiency of the urban economy plus the maintenance of social stability. Conversely, providing lower and middle-income families public housing could make contribution to minimizing social instability resulted from equal right shortage for housing, and then achieving a well-integrated functioning social mix. Thirdly, residents often concern to quality services accessibility and other amenities since they have profound impact on inhabitants wellbeing. This requires reasonable access to barrier-free infrastructure and free leisure and sports facilities within easy access of homes. Also, this needs rational access to schools, health services, shopping facilities and open spaces as well as proximity to place for the elderly to live in the neighborhood [11]. Thus, the living quality can be largely improved through enhancing the integrative capacities of social and other infrastructure.

\section{ECO-CITY OBJECTIVE EXAMINATION FRAMEWORK FORMULATION}

A. Index system establishment, index selection and index reference value determination

As shown in Table 1. The objective examination framework consists of three criterion layers. The first criterion layer is eco-city comprehensive evaluation index. The second criterion layer includes three indexes like friendly environment, sustainable economy and social harmony. The third criterion layer includes quantitative indexes. Based on research reports about sustainable development and eco-city evaluation, high-frequency indexes are chosen by frequency statistics. Also important and well-targeted indexes are chosen by the Delphy consultation, expert group discussion, case investigation. Finally, 31 quantitative indexes are determined after comprehensively considering correlation between indicators, independence of index and availability of data. The reference value of index is determined according to the criteria The United Nations Environment Programme, The State Environmental Protection Administration, The National Development and Reform Commission and The Ministry of Housing and Urban-Rural Development etc. 
TABLE I OBJECTIVE EXAMINATION FRAMEWORK FOR ECO-CITY

\begin{tabular}{|c|c|c|c|c|c|c|}
\hline $\begin{array}{l}\text { The first } \\
\text { Criterion Layer }\end{array}$ & $\begin{array}{l}\text { The second } \\
\text { Criterion Layer }\end{array}$ & Subject & $\begin{array}{l}\text { Index } \\
\text { Number }\end{array}$ & The third Criterion Layer & $\begin{array}{r}\text { Reference } \\
\text { Value }\end{array}$ & Basis \\
\hline \multirow{31}{*}{$\begin{array}{l}\text { Eco - city } \\
\text { Comprehensive } \\
\text { Evaluation } \\
\text { Index }\end{array}$} & \multirow{16}{*}{$\begin{array}{r}\text { Friendly } \\
\text { Environment }\end{array}$} & \multirow{2}{*}{$\begin{array}{c}\text { Water } \\
\text { Resource }\end{array}$} & 1 & sewage treatment rate & $\geq 70 \%$ & PRC MEP \\
\hline & & & 2 & reuse rate of industrial water & $\geq 90 \%$ & The UNEP \\
\hline & & \multirow[b]{2}{*}{ Energy } & 3 & utilization rate of renewable energy & $\geq 15 \%$ & The UNEP \\
\hline & & & 4 & energy consumption $/ \mathrm{m}^{2}$ & $\begin{array}{l}<90 \mathrm{kw} \cdot \mathrm{h} /( \\
\mathrm{m} \cdot \text { year })\end{array}$ & PRC MOHURD \\
\hline & & \multirow{2}{*}{$\begin{array}{r}\text { Land } \\
\text { Resource }\end{array}$} & 5 & construction land area per capital & $\geq 80 \mathrm{~m}_{2}^{2} \leq 120 \mathrm{~m}$ & PRC MOHURD \\
\hline & & & 6 & urban construction land /urban area & $\leq 30 \%$ & PRC MOHURD \\
\hline & & \multirow{3}{*}{ Air Quality } & 7 & daily average concentration of PM10 & $\geq 347$ days & PRC MEP \\
\hline & & & 8 & daily average concentration of $\mathrm{CO}_{2}$ & $\geq 347$ days & PRC MEP \\
\hline & & & 9 & daily average concentration of $\mathrm{NO}_{2}$ & $\geq 347$ days & PRC MEP \\
\hline & & \multirow{2}{*}{ Water Quality } & 10 & $\begin{array}{l}\text { standard-reaching rate of water quality in } \\
\text { centralized drinking water source }\end{array}$ & $100 \%$ & The UNEP \\
\hline & & & 11 & $\begin{array}{l}\text { standard-reaching rate of water quality in } \\
\text { urban water environment function area }\end{array}$ & $100 \%$ & The UNEP \\
\hline & & \multirow{2}{*}{$\begin{array}{r}\text { Waste } \\
\text { Treatment }\end{array}$} & 12 & domestic wastes utilization rate & $\geq 70 \%$ & PRC MEP \\
\hline & & & 13 & industrial solid wastes utilization rate & $\geq 95 \%$ & The UNEP \\
\hline & & Noise & 14 & the average equivalent sound level & $\leq 50$ decibel & PRC MEP \\
\hline & & \multirow{2}{*}{$\begin{array}{l}\text { Park Green } \\
\text { Space }\end{array}$} & 15 & green cover percentage of urban area & $\geq 40 \%$ & Current situation \\
\hline & & & 16 & coverage of $500 \mathrm{~m}$ service radius & $\geq 80 \%$ & Current situation \\
\hline & \multirow{5}{*}{$\begin{array}{l}\text { Sustainable } \\
\text { Economy }\end{array}$} & \multirow{2}{*}{$\begin{array}{l}\text { Economic } \\
\text { Development }\end{array}$} & 17 & energy consumption /1000 thousand GDP & $\leq 1.4 \mathrm{t}$ & PRC MEP \\
\hline & & & 18 & water consumption /1000 thousand GDP & $\leq 150 \mathrm{~m}^{3}$ & PRC MEP \\
\hline & & $\begin{array}{l}\text { Industry } \\
\text { Structure }\end{array}$ & 19 & the proportion of tertiary industry & $\geq 50 \%$ & The NDRC \\
\hline & & Income Level & 20 & Engel coefficient & $\leq 40 \%$ & The NDRC \\
\hline & & $\begin{array}{l}\text { Employment } \\
\text { Level }\end{array}$ & 21 & registered unemployment rate in town & $\leq 2.2 \%$ & $\begin{array}{l}\text { International } \\
\text { advanced city }\end{array}$ \\
\hline & \multirow{10}{*}{$\begin{array}{l}\text { Social } \\
\text { Harmony }\end{array}$} & $\begin{array}{l}\text { Housing } \\
\text { Security }\end{array}$ & 22 & housing security rate & $\geq 90 \%$ & PRC MOHURD \\
\hline & & Medical Level & 23 & sickbeds /1000 people & 10 & advanced city \\
\hline & & \multirow{2}{*}{$\begin{array}{l}\text { Recreation and } \\
\text { Sports Facility }\end{array}$} & 24 & library collections per capital & $\geq 2.3$ & The NDRC \\
\hline & & & 25 & public sports facilities area per capital & $\geq 1.5 \mathrm{~m}^{3}$ & The NDRC \\
\hline & & \multirow{2}{*}{$\begin{array}{l}\text { Technology and } \\
\text { education }\end{array}$} & 26 & fiscal education spending of GDP & $\geq 4 \%$ & advanced city \\
\hline & & & 27 & R\&D spending of GDP & $\geq 2 \%$ & advanced city \\
\hline & & \multirow{2}{*}{$\begin{array}{r}\text { Income } \\
\text { Distribution }\end{array}$} & 28 & income ratio of urban and rural residents & $<2.2$ & advanced city \\
\hline & & & 29 & Gini Coefficient & $\leq 0.38$ & The NDRC \\
\hline & & \multirow{2}{*}{$\begin{array}{l}\text { Transportation } \\
\text { Convenience }\end{array}$} & 30 & public transport share rate & $\geq 50 \%$ & advanced city \\
\hline & & & 31 & average commute time & $\leq 30 \mathrm{~min}$ & advanced city \\
\hline
\end{tabular}

\section{B. Indicator weight determination}

This paper refers to lots of information including relevant research undertaken by Tianjin Academy of Social Sciences and Tianjin Urban Planning and Design Institute, research conclusions of the domestic well-known experts and survey taken by graduate students etc. Indicator weight of the second criterion layer is determined by summarizing results above. As shown in the following Table 2. 
TABLE II INDICATOR WEIGHT OF THE SECOND CRITERION LAYER

\begin{tabular}{|l|l|c|}
\hline \multirow{2}{*}{ The First Criterion Layer } & The Second Criterion Layer & Indexes weight of The Second Criterion Layer \\
\hline \multirow{3}{*}{ Eco - city Comprehensive Evaluation Index } & Environmental subsystem & 0.38 \\
\cline { 2 - 3 } & Economic subsystem & 0.32 \\
\cline { 2 - 3 } & Social subsystem & 0.30 \\
\hline
\end{tabular}

\section{The calculation method of index value}

1) Normalization of the third criteria layer indicator

The data need to be normalized before the analysis because indicator type is different and there are big differences in the original data. In order to eliminate the influence of the differences between indicators and units, the original data must be converted into numbers within the interval $[0,1]$. The formula for standardization is as follows:

$$
\begin{aligned}
& \mathrm{Si}=(\mathrm{Ci}-\mathrm{Cmin}) /(\mathrm{Cmax}-\mathrm{Cmin}) \quad \text { (positive indicator } \\
& \text { processing) }
\end{aligned}
$$

$$
\mathrm{Si}=1-(\mathrm{Ci}-\mathrm{Cmin}) /(\mathrm{Cmax}-\mathrm{Cmin}) \quad \text { (reverse indicator }
$$
processing)

$\mathrm{Si}$ is the normalized indicator value of the third criteria layer, $\mathrm{Ci}$ is the current data of city evaluated, $\mathrm{Cmax}$ is the maximum of indicator data of related cities, Cmin is the minimum of indicator data of related cities.

2) Calculation of the second criteria layer indicator value

The standard value of the second criteria layer indicator is calculated according to arithmetic mean value of the third criteria layer indicator. The formula for standardization is as follows:

$$
\sum_{\mathrm{V}=1}^{m} S i
$$

$\mathrm{V}$ is the indicator value of the second criteria layer, $\mathrm{m}$ is the number of the third criteria layer indicators in corresponding second criteria layer. Also the normalized value is multiplied by the respective weights and then adds to get the U. The formula is as follows:

\section{$\mathrm{U}=\mathrm{W} \times \mathrm{V}$}

$\mathrm{U}$ is a indicator value of the second criteria layer. $\mathrm{W}$ is the second criteria layer indicator weight.

\section{3) Eco - city Comprehensive Evaluation Index Calculation}

Eco - city Comprehensive Evaluation Index is the first criteria layer indicator. The formula for ECI calculation is as follows:

$$
\mathrm{ECI}=\sum_{i=1}^{\mathrm{N}} \mathrm{T} i U_{\mathrm{i}}
$$

ECI is eco - city comprehensive evaluation index value. $\mathrm{Ui}$ is a indicator value of the second criteria layer. $\mathrm{Ti}$ is a indicator weight of the second criteria layer. $\mathrm{N}$ is the number of indicators of the second criteria layer. In this paper, $\mathrm{N}$ is 3 .
In order to evaluate the overall level of development of eco-city, this article designed a classification to determine the degree of development of eco-city by referring to the various domestic and foreign comprehensive index classification methods. An Eco-city comprehensive evaluation classification criterion is as follows:

TABLE III ECO-CITY COMPREHENSIVE EVALUATION CLASSIFICATION CRITERIA

\begin{tabular}{|c|l|l|}
\hline Grade & ECI & Ecological Degree \\
\hline 1 & $0.75-1.0$ & Highest \\
\hline 2 & $0.4-0.75$ & Higher \\
\hline 3 & $0.25-0.4$ & General \\
\hline 4 & $0-0.25$ & Weak \\
\hline
\end{tabular}

\section{INNOVATIVE AND INTEGRATIVE POLICIES FOR ECO-CITY DEVELOPMENT}

\section{A. Information}

Information is a required condition for the eco-city since it is helpful for governments to improve understanding of urban sustainability problems. Governments can extend the boundaries of the possibility of accepting public perspectives for eco-city development. Secondly, better understanding of city's current situation and reasonable forecasting are linked to the development of urban indicators. Meanwhile, information systems including GIS (geographical information system) are recommended because they have extensive capacity that is under-utilized to offer governments such as measures for current performance including reporting systems for the environment, cities and institutions. Environmental carrying capacity of cities should be defined through measuring the ecological footprint in their bio-regional context in order to establish relevant database. Also, to anticipate a more sustainable future direction for urban development, governments could exploit the potential of scenario building, strategic vision making and simulation techniques which rely on the linking of information systems [12].

\section{B. Participation}

Better decisions are hard to implement and be supported because the public is not an informed participation in the process. At national level, participation contributes to broadening the constituencies which governments involve in policy development. It is also important for agreement, providing a basis for widespread commitment to change. Participation needs more attention by governments. Policy makers have a key responsibility to provide the public with 
alternative visions of what is desirable and possible, to stimulate deliberation about them, provoke a re-examination of premises and values, and thus broaden the range of potential responses and deepen society's understanding of itself. A successful approach is community based urban design participation. It allows for intensive interaction between stakeholders to develop sustainable designs for urban areas at a variety of scales.

\section{Evaluation}

Within the context of the eco-city, evaluation of projects, policies and plans is significant to avoid repeating mistakes and to refine approaches which have been widely distributed and applied. Evaluation contributes to defining progress toward objectives and analyzing priorities according to implementation experiences. Thus, developing more appropriate evaluation tools and databases are primary requirements for governments. It is crucial to provide different partners with practical form and operational tool to enable each technical or financial partner to ascertain the role they would make entire effort to improve living quality of eco-city [10]. Moreover, evaluation should link up with other innovative techniques for sustainability planning. For example, computerized geographical information systems are recommended to be established for data collection and analysis to monitor building and planning. Additionally, environmental impact statement (EIS) and environmental impact assessment (EIA) can be used as common techniques for addressing both the positive and negative impacts of development proposals. EIS and EIA allow for a much greater degree of rational communication to enter the development process and the government work. It contributes to opening up lines of discussion and argument between governments and other groups, which may previously have been marginalized from policy development process.

\section{Education}

Good education is a key step in achieving the eco-city. Currently, lots of people unwilling to change living habits which lead to unsustainability of urban environment. More environmentally friendly lifestyles cannot be imposed; rather they are developed through innovative partnerships rooted in the local culture [8]. Accordingly, developing more positive cultural perceptions about environmental education is needed to pay attention to. Relevant policies should be designed for environmental education to provide residents of eco-city with active education to achieve more sustainable attitudes and behaviors. Recent comparative research states that environmental education should be integrated into mainstream curricula at school and university level early and preferably. Once individuals realize the importance of eco-friendly lifestyle to eco-city construction and development through interdisciplinary learning and research, they will also show a greater tendency to change their lifestyles. An essential education task for government is to broaden understanding of ecological decline in cities though promoting wider environmental literacy in the community, in business, and across agencies. Besides residents, education at all levels should be required and strengthened including planners, developers, builders and urban administrators etc. This can be realized by improving teacher training programs for teachers at different levels, developing seminars and conferences for professionals and providing free lectures for communities to present models of sustainable lifestyle in eco-city.

\section{CONCLUSIONS}

Eco-city is the most important efforts made towards sustainable urban development. Eco-city objective examination framework will attract more attentions of authorities and planners through arguing for the necessity and urgency of eco-city construction and implementation. Four objectives need to be achieved during eco-city construction: resource efficiency, friendly environment, sustainable economy and social harmony. Developing an ultimate checklist after eco-city performance assessment can be as navigation light to cope with challenges for progress of eco-city. Information, participation, evaluation, diffusion and education should be considered to promote best practice to encourage and facilitate the exchange of experiences between cities. It is necessary to encourage the conservation of the natural environment of urban areas and advocate for eco-friendly lifestyles through education, community engagement, and policy promotion. It can also provide authorities and planners relatively practical strategies to minimize the obstacles in the way of eco-city development and then promote urban development towards environmental, social and economic sustainability.

\section{REFERENCES}

[1] He J and Bao CK et al. (2010), Framework for integration of urban planning, statistic environmental assessment and ecological planning for urban sustainability within the context of China, Environmental Impact Assessment Review, (6): pp.549-560

[2] Todorov VI \& Marinova D. 2009, Models of Sustainability, 18th World IMACS Congress, Cairns, Australia.

[3] Gaffron P., Huismans G. \& Skala, F. (2005), Ecocity Book 1: A better place to live, European Commission

[4] Zhu Y.X. \& Lin B. (2004). Sustainable housing and urban construction in China, Energy and Buildings, (12): pp. 1287-1297.

[5] He K.B., Huo, H. \& Zhang, Q. (2002), Urban air pollution in China: Current status, characteristics, and progress. Annual Review of Energy and the Environment, (1): pp. 397-431

[6] Harding, R. (2006). Ecologically sustainable development: origins, implementation and challenges', Desalination, (1-3): pp.229-239.

[7] Newman, P. 2005, 'Urban design and transport', in Goldie, J., Douglas, B. \& Furnass, B. (eds), In Search of Sustainability, CSIRO publishing, Melbourne, pp. 123-126.

[8] Zhuang, Y. (2015). Confucian ecological vision and the Chinese eco-city, Cities, (451): pp. 142-147

[9] Zhao, J.Z. 2011, Towards sustainable cities in China: analysis and assessment of some Chinese cities in 2008, Springer Science + Business Media, New York.

[10] Young, D. \& Keil, R. (2010), Reconnecting the disconnected: The politics of infrastructure in the in-between city, Cities,(2): pp.87-95

[11] Egger, S (2006), Determining a Sustainable City Model, Environmental Modeling\&Software, (9): pp.1235-1246

[12] Stevensa,D., Dragicevica,S.\&Rothley, K. (2007), iCity: A GIS-CA modelling tool for urban planning and decision making, Environmental Modelling \& Software, (6): pp.761-773. 